\title{
Time Evolution of Rheology of Cement Pastes Affected by Mixture Design and Mixing Procedure
}

\author{
by Azadeh A. Asghari, Dimitri Feys, and Geert De Schutter
}

\begin{abstract}
Robustness is defined as the capacity of cement-based materials to retain fresh properties when subjected to either small variations in the constituent elements or small changes in the mixing procedure. Compared to normal concrete, self-consolidating concrete (SCC) may show less tolerance to those changes. Most robustness studies focus on initial rheological properties or workability, but concentrate less on the evolution of these properties within the first hour(s). This paper presents the results of an investigation aimed at evaluating the change of yield stress and plastic viscosity with time of cement pastes with SCC consistency, which is mainly affected by variations in the water content and the adding time of the superplasticizer. A change in water content also influences the initial rheological properties, and these differences are amplified over time. The difference due to the different adding time of the superplasticizer is, however, reduced or even reversed over time.
\end{abstract}

Keywords: cement paste; constituent elements; mixing procedure; rheology; robustness; workability loss.

\section{INTRODUCTION}

Self-consolidating concrete (SCC) has less tolerance to small changes in the quantities and properties of constituent materials and mixing procedure compared to conventional vibrated concrete. Those slight changes induce small alterations in the rheological properties of SCC, ${ }^{1,2}$ which can lead to segregation in case of a decrease in yield stress or plastic viscosity, or a loss of filling capacity in case of an increase in yield stress or plastic viscosity. Controlling the variations in the rheological properties is essential to ensure proper characteristics of SCC during mixing, transport, and placement. ${ }^{3-7}$ If the initial rheological properties and their change as a function of time are inadequate, mechanical properties and durability of the cast structure can be negatively affected. ${ }^{8}$

Most robustness studies have focused on the influence of mixture design, constituent material properties, and mixing procedure on the rheological properties of concrete. The paste component of the concrete plays hereby a crucial role, as the rheological properties are strongly related to the water-cementitous materials ratio $(w / \mathrm{cm})$, the presence of supplementary cementitious materials, chemical admixtures, temperature, and shear history. ${ }^{9-13}$ An incorrect assessment of the sand moisture content is considered to significantly influence the cement paste composition and properties (larger relative change in water content) in a more prominent way than any change in rheological properties induced by the sand content.

On paste level, the initial rheological properties, mostly measured between 10 and 30 minutes after water addition, are significantly affected by $w / \mathrm{cm}$, sometimes showing an exponential relationship with the change in water content. ${ }^{14-16}$ Furthermore, in cement pastes (or concrete mixtures) with different $w / \mathrm{cm}$, different parameters are dominant in controlling the robustness, resulting in some apparent disparity in research conclusions..$^{3-6,17,18}$ Employing superplasticizers (SP, also known as high-range water-reducing admixtures) causes dispersion of flocculated cement grains and the release of entrapped water. ${ }^{19-22}$ Bonen and $\mathrm{Shah}^{23}$ reported the effects of the SP content on the flow properties of concrete, revealing that the robustness of the flow is proportional to the mass ratio of SP to binder. Mixture composition and mixing procedures can affect the efficiency of the SP in decreasing the water demand in cement paste ${ }^{24,25}$ : increasing mixing intensity decreases both plastic viscosity and yield stress dramatically, ${ }^{15,26,27}$ unless the mixture is overmixed. SP adsorption on cement is also affected by the concentration of sulfate ions in the interstitial solution..$^{28,29}$ In addition, the time of adding the SP can change the initial rheological properties of SCC dramatically. ${ }^{30-35}$ The effect of limestone filler on the initial rheological properties has been studied by Carlsward et al. ${ }^{36}$ showing that limestone filler has small influence on the plastic viscosity and the yield stress. Bonen et al. ${ }^{2}$ reported that incorporation of high-specific-gravity fine materials such as limestone, slag, and dolomite increases the SCC robustness.

Most of these studies solely focus on the robustness of the initial rheological properties. However, their change with time should also be considered, especially when focusing on ready mix applications, as transport times can be extensive. The change in rheological properties with time is generally induced by two factors: physical factors (such as flocculation, destruction, and restructuring of the microstructure) and chemical factors (including cement hydration and decrease in free water content) ${ }^{37}$ Typically, the physical factors (which are reversible) are considered as thixotropy, while the chemical factors are associated to the non-reversible workability loss, although recent work has shown that the distinction is not so straightforward. ${ }^{13,38}$ Cement hydration, mixture composition, and the interaction between the binder particles and chemical admixtures are dominant factors which influence the workability loss over

ACI Materials Journal, V. 115, No. 5, September 2018.

MS No. M-2017-389.R1, doi: 10.14359/51702348, was received October 12, 2017, and reviewed under Institute publication policies. Copyright (C) 2018, American Concrete Institute. All rights reserved, including the making of copies unless permission is obtained from the copyright proprietors. Pertinent discussion including author's closure, if any, will be published ten months from this journal's date if the discussion is received within four months of the paper's print publication. 
Table 1-Reference Mixture Designs 1, 2, and 3, $\mathrm{kg} / \mathrm{m}^{3}\left(\mathrm{lb} / \mathrm{yd}^{3}\right)$

\begin{tabular}{c|c|c|c|c|c|c|c|c|c}
\hline & Cement & Limestone filler & Fly ash & Silica fume & Water & SP1 & SP2 & VMA & $w / p$ \\
\hline $\begin{array}{c}\text { Mixture } \\
\text { Design 1 }\end{array}$ & $808(1362)$ & $808(1362)$ & - & - & $444(748)$ & $3.47(5.85)$ & - & - \\
\hline $\begin{array}{c}\text { Mixture } \\
\text { Design 2 }\end{array}$ & $1013(1707)$ & - & $351(592)$ & $35(59)$ & $533(898)$ & - & $6.80(11.46)$ & $0.88(1.48)$ & 0.38 \\
\hline $\begin{array}{c}\text { Mixture } \\
\text { Design 3 }\end{array}$ & $872(1470)$ & $654(1102)$ & - & - & $479(807)$ & $2.53(4.26)$ & - & - & 0.31 \\
\hline
\end{tabular}

time. ${ }^{39}$ In addition, differences in the quantity and composition of superplasticizer influence the cement hydration process and thus affect the workability loss in an additional manner. ${ }^{40-43}$ Correlations between mixture compositions, the initial rheological properties of the cementitious system, and the development of rheological properties over time have been investigated by several researchers. ${ }^{4-47}$ It is reported that the change of rheological properties as a function of time in cement-based materials is strongly influenced by superplasticizer type and dosage, $w / \mathrm{cm}$, and cement type. ${ }^{46,48}$ Gołaszewski and Szwabowski ${ }^{46}$ investigated the effect of polycarboxylate superplasticizer-cement ratio $(\mathrm{Sp} / \mathrm{C}), \mathrm{w} / \mathrm{cm}$, and time on the rheological behavior of fresh cement pastes. For $S p / C$ from 0 to $2.0 \%$ and $w / \mathrm{cm}$ of 0.25 to 0.50 , it has been indicated that with an increase in SP dosage, the initial flowability, and flowability retention over time increase because of plasticizing and retardation induced by the superplasticizer. At low $S p / C$, similar trends have been observed for yield stress and plastic viscosity, while in the case of high $S p / C$, the yield stress and plastic viscosity deceased over the elapsed time. ${ }^{46}$ Gołaszewski and Szwabowski ${ }^{46}$ also concluded that the type and dosage of superplasticizers affect the rheological behavior of cement mortars. Polycarboxylate ether (PCE) superplasticizer makes mortars with lower workability loss compared to naphtalene sulphonate acid (SNF) superplasticizers.

Petit et al..$^{37,48,49}$ investigated the influence temperature on the evolution of rheological properties with time. When expressing the elapsed time as a function of the final setting time, nearly linear increases were found for the yield stress and plastic viscosity. However, especially for PCE-based SP, the evolution of the rheological properties with time could follow a more complex pattern when temperature was below a certain threshold, dependent on the mixture design.

\section{RESEARCH SIGNIFICANCE}

In this paper, the robustness of the "loss of workability" of flowable cement pastes is discussed. Similar to performing a robustness study on the initial rheological properties, the change in their time evolution is described. The influence of the change in water content, SP dosage, varying mixing time, mixing speed and different addition time of SP is demonstrated. The results are compared to the influence of these parameters on the initial rheological properties, ${ }^{50}$ and a more accurate vision on robustness of cement paste, and also concrete, can be developed by taking into account the time dependency of the rheological properties.

\section{Materials}

\section{EXPERIMENTAL PROGRAM}

Three different cement pastes with SCC consistency were prepared based on SCC mixtures commonly used in Europe and North America. ${ }^{50}$ Mixture Designs 1 and 3 are based on the powder-type approach. Mixture Design 1 was prepared with a water-powder ratio $(w / p)$ of 0.275 . The powder is composed of 50\% Type I/II cement (according to ASTM $\mathrm{C} 150$ ) and $50 \%$ finely ground limestone (by mass). Mixture Design 3 is based on the same principle, but the powder consists of $57 \%$ cement and $43 \%$ limestone filler, while $w / p$ $=0.31$. Both mixture designs are produced with an efficient PCE-based superplasticizer. As will be discussed further, this SP, named SP 1, has a relatively short workability retention.

Mixture Design 2 is based on a viscosity-modifying agent (VMA)-type mixture design using silica fume (SF) and Class C fly ash (FA) as a supplementary cementitious material $(\mathrm{SCM})$, with a more elevated $w / p(=0.38)$ compared to the other mixture designs. A different PCE (SP 2), from a different manufacturer, was used. This SP had relatively long workability retention. A VMA has been added to Mixture Design 2 to assure stability. The VMA is from the same manufacturer as SP 2 to prevent compatibility problems. The mixture proportions of the cement pastes are listed in Table 1. For all reference cement pastes, the amount of each SP was determined to reach a mini-slump flow value of $330 \pm 10$ $\mathrm{mm}(11.8 \pm 0.4$ in.) at 7 minutes after mixing, ensuring SCC consistency. It should be noted that halfway the experiments on Mixture Design 2, a new delivery of cement causes some modifications in the SP demand, and in the rheological properties.

\section{Mixing procedure}

The preparation of the cement pastes occurred at the lowest speed available in a small kitchen-style mixer. The water addition time is taken as reference time $\left(t_{0}\right)$, while the reference mixing procedure is presented in Table 2 . The total mixing duration is 6 minutes, after contact between cement and water. The repeatability of the mixture and the mixing procedure, the influence of water, and the influence of SP variations were investigated by employing the reference mixing procedure.

\section{Variables}

Four main variables were evaluated in this study for the mixture designs:

- Water content modifications inducing a change in $w / p$ of approximately \pm 0.01 and \pm 0.02 , which corresponds to \pm 5 and $\pm 10 \mathrm{~L}$ of water in $1 \mathrm{~m}^{3}\left(1.01\right.$ and $\left.2.02 \mathrm{gal} . / \mathrm{yd}^{3}\right)$ 
Table 2-Mixing procedures (reference, short, and long)

\begin{tabular}{|c|c|c|c|c|}
\hline \multirow[b]{2}{*}{ Step } & \multicolumn{3}{|c|}{ Duration } & \multirow[b]{2}{*}{ Action } \\
\hline & Reference & Short & Long & \\
\hline 1 & $30 \mathrm{~s}$ & $30 \mathrm{~s}$ & $30 \mathrm{~s}$ & $\begin{array}{c}\text { Dry } \\
\text { materials }\end{array}$ \\
\hline $2\left(=t_{0}\right)$ & $1 \mathrm{~min}$ & $30 \mathrm{~s}$ & $2 \min$ & $\begin{array}{l}\text { Adding } \\
\text { water }\end{array}$ \\
\hline 3 & $1 \mathrm{~min}$ & $1 \mathrm{~min}$ & $1 \mathrm{~min}$ & Scraping \\
\hline 4 & $30 \mathrm{~s}$ & $30 \mathrm{~s}$ & $30 \mathrm{~s}$ & Mixing \\
\hline 5 & $2 \min$ & $1 \mathrm{~min}$ & $4 \min$ & $\begin{array}{l}\text { Add SP/ } \\
\text { VMA }\end{array}$ \\
\hline 6 & $30 \mathrm{~s}$ & $30 \mathrm{~s}$ & $30 \mathrm{~s}$ & Scraping \\
\hline 7 & $1 \mathrm{~min}$ & $1 \mathrm{~min}$ & $1 \mathrm{~min}$ & Mixing \\
\hline Duration since $t_{0}$ & $6 \mathrm{~min}$ & $4.5 \mathrm{~min}$ & $9 \min$ & - \\
\hline Total rotations & $613 / 1047$ & 409 & 1022 & - \\
\hline
\end{tabular}

Note: Values in italic indicate times when speed was increased to study influence of mixing speed.

of concrete, respectively. The corresponding concrete mixture designs can be found in Asghari et al. ${ }^{50}$

- The superplasticizer content was varied by $\pm 5 \%$ and $\pm 10 \%$, keeping every other parameter constant.

- The reference mixing procedure incorporated a delayed addition of the dispersing admixture by 2.5 minutes, based on the experience of the research team with the corresponding concretes. In the case of immediate SP addition, the SP was physically mixed with the water prior to addition to the cement. However, the VMA for Mixture Design 2 was added at the same delay time, regardless of the adding time of the SP.

- The modifications in mixing energy correspond to the mixing speed and the mixing time. It is expressed as the total estimated number of rotations of the paddle in the mixer. Table 2 shows the change in mixing energy by switching the setting on the mixer (setting 1: $2.27 \mathrm{rps}$ or 2: $4.68 \mathrm{rps}$ ). The mixing speed was only increased in Steps 5 and 7 of the mixing procedure to ensure all materials remain in the mixing bowl. The mixing time variations are shown also shown in Table 2. The short mixing time is the shortest feasible to assure a homogeneous mixture. The longest mixing time is the longest feasible to evaluate the mini slump flow of the mixture and to start the rheological procedure at 15 minutes.

\section{Rheometry}

A standard rheometer, typically used in the polymer industry (Fig. 1), was employed to measure the rheological properties of the cement pastes. A coaxial cylinder geometry was selected for these tests. Both inner and outer cylinders were sandblasted to limit slippage. The inner cylinder radius $\left(R_{i}\right)$ measures $13.33 \mathrm{~mm}$ (0.5248 in.), the outer cylinder radius $\left(R_{o}\right)$ is $14.56 \mathrm{~mm}(0.5732 \mathrm{in}$.$) , and the height (h)$ is $40.00 \mathrm{~mm}$ (1.575 in.). Prior to each measurement of the rheological properties, the sample was pre-sheared for 60 seconds at a shear rate of $100 \mathrm{~s}^{-1}$ to ensure the same refer-

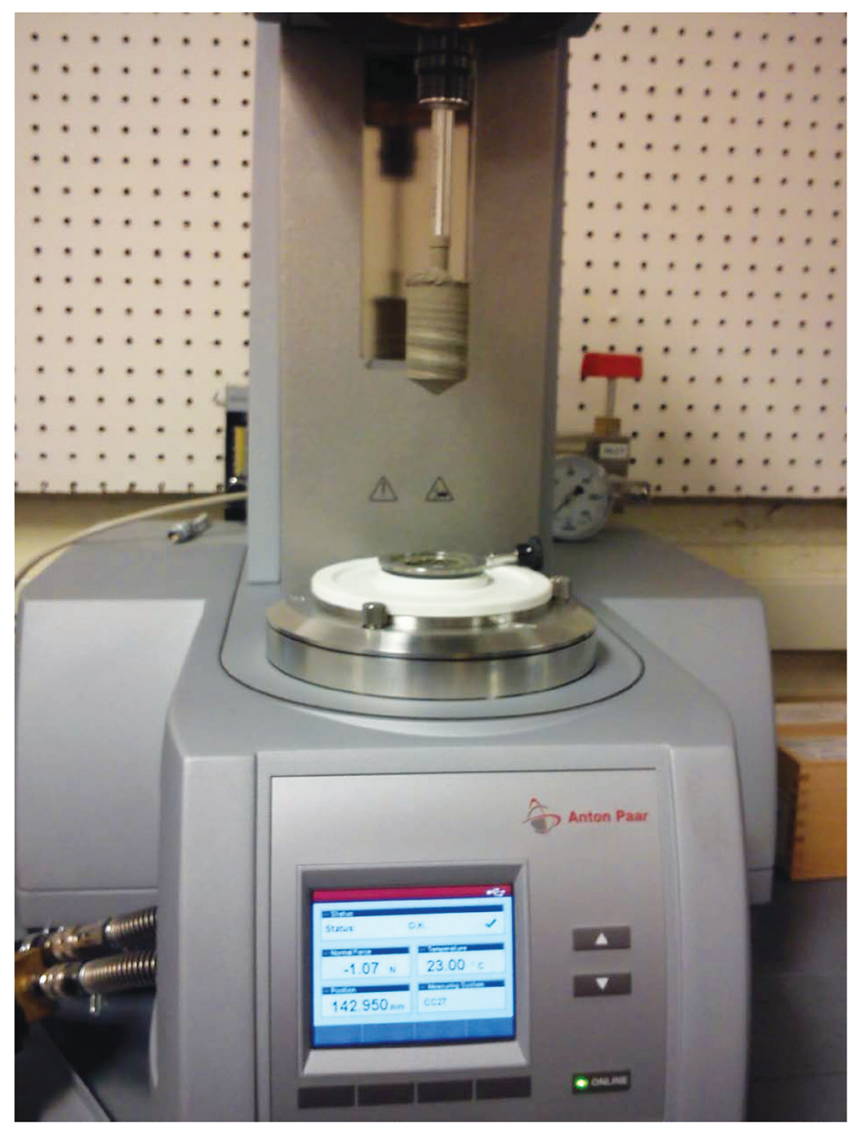

Fig. 1-MCR rheometer, equipped with sandblasted coaxial cylinders.

ence state of the sample for each measurement. Based on previous experiences by the research team, this time seemed the shortest time possible to reach equilibrium for the evaluated mixtures. The rheological properties were determined by measuring the torque response to a stepwise decreasing function of the shear rate: the shear rate was decreased in 10 intervals, with a duration of 5 seconds each, from 100 to $10 \mathrm{~s}^{-1}$. From the raw torque and rotational velocity data, the yield stress and plastic viscosity (Eq. (1)) were determined based on the Reiner-Riwlin principle ${ }^{51,52}$

$$
\tau=\tau_{0}+\mu_{p} \dot{\gamma}
$$

Equation (1) represents the Bingham model, which is used in the derivation of the Reiner-Riwlin equation (refer to Feys et al. $\left.{ }^{52}\right) . \tau$ represents the shear stress $(\mathrm{Pa}) ; \tau_{0}$ is the yield stress $(\mathrm{Pa}) ; \mu_{p}$ is the plastic viscosity (Pa s); and $\dot{\gamma}$ is the shear rate $\left(\mathrm{s}^{-1}\right)$. While the yield stress is defined as the stress needed to start the flow, the plastic viscosity is the resistance of the material to enhance in flow rate once the yield stress is exceeded. ${ }^{14}$

The time evolution of the rheological properties is taken as the (linear) slope of four consecutive measurements, performed at 15 (initial), 30, 45, and 60 minutes after initial contact between cement and water. The temperature in the rheometer is kept constant at $23^{\circ} \mathrm{C}\left(73.5^{\circ} \mathrm{F}\right)$ to eliminate the influence of temperature on the time evolution of the rheological properties..$^{37,48}$ 
Mix design 1

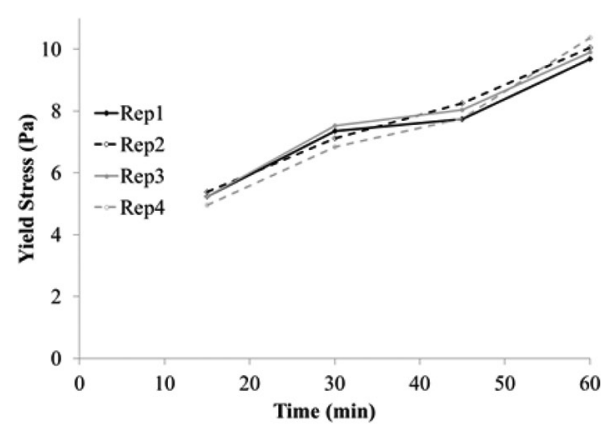

Mix design 2

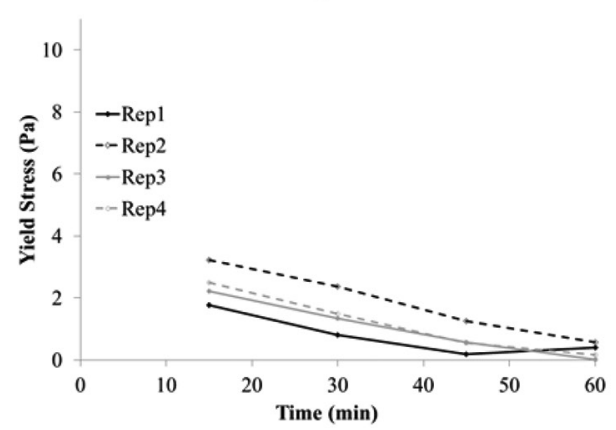

Mix design 3

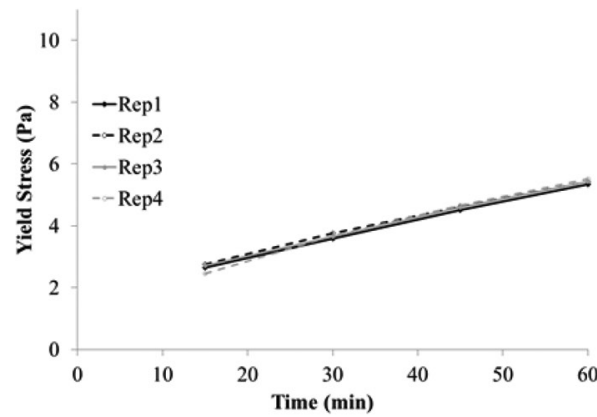

Mix design 1

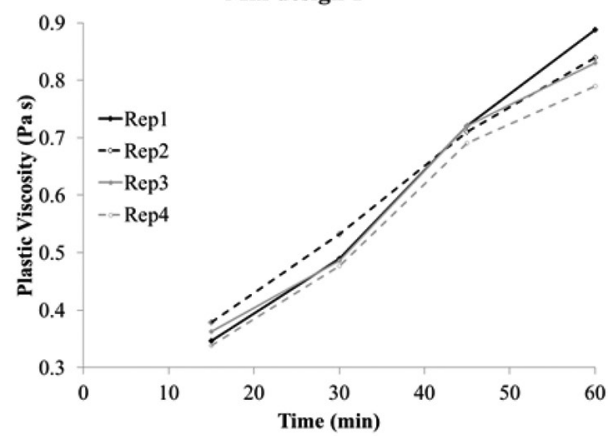

Mix design 2

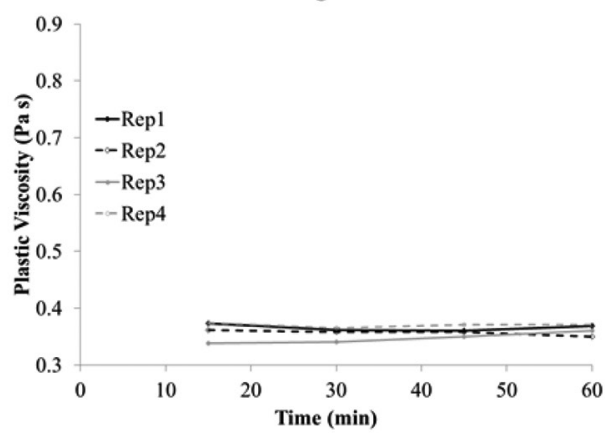

Mix design 3

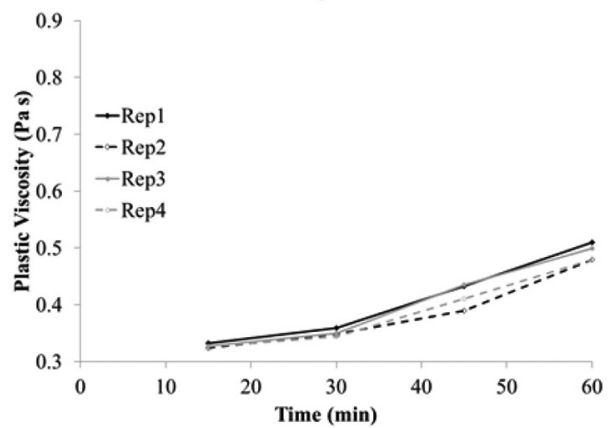

Fig. 2-Evolution of plastic viscosity and yield stress over time, repeated four times. (Note: 1 Pa $=0.145$ psi.)

\section{Repeatability}

\section{RESULTS AND DISCUSSION}

A 90\% confidence interval for all three mixtures is calculated for the increase in yield stress (in $\mathrm{mPa} / \mathrm{min}$ ) and plastic viscosity (in $\mathrm{mPas} / \mathrm{min}$ ) with time based on four repetitive productions of the cement pastes. Figure 2 shows the evolution of plastic viscosity and yield stress with time for all mixtures, and all results are summarized in Table 3. Table 3 contains the average increase in plastic viscosity and yield stress for all reference mixtures, as well as the corresponding confidence intervals. In Table 3, two sets of results are shown for Mixture Design 2, as these correspond to the different cement deliveries. The influence of water and SP content is relative to the first reference for Mixture Design 2, while the adding time and mixing energy will be compared to the second reference.

Evaluating the numbers in Table 3, the difference between the two SP employed is clearly visible. Mixtures prepared with SP 1 (Mixture Designs 1 and 3) show a steady increase of yield stress and plastic viscosity with time. Mixture Design 2, in which SP 2 with long workability retention is
Table 3-Average values for plastic viscosity and yield stress and $90 \%$ confidence intervals, based on four measurements, for Mixtures 1, 2, and 3

\begin{tabular}{|c|c|c|c|c|}
\hline & \multirow[b]{2}{*}{$\begin{array}{l}\text { Mixture } \\
\text { Design } 1\end{array}$} & \multicolumn{2}{|c|}{ Mixture Design 2} & \multirow[b]{2}{*}{$\begin{array}{l}\text { Mixture } \\
\text { Design } 3\end{array}$} \\
\hline & & $\begin{array}{c}\text { CEM } \\
\text { delivery } 1\end{array}$ & $\begin{array}{c}\text { CEM } \\
\text { delivery } 2\end{array}$ & \\
\hline $\begin{array}{c}\text { Average increase in } \\
\text { plastic viscosity, } \\
\text { MPas } / \mathrm{min}\end{array}$ & 10.3 & -0.1 & 1.2 & 3.7 \\
\hline$+90 \%$ confidence limit & 12.2 & 0.5 & 1.4 & 4.3 \\
\hline$-90 \%$ confidence limit & 8.6 & -0.7 & 1.0 & 3.1 \\
\hline $\begin{array}{c}\text { Average increase in } \\
\text { yield stress, } \mathrm{MPa} / \mathrm{min}\end{array}$ & 91 & -49 & 9 & 62 \\
\hline$+90 \%$ confidence limit & 112 & -26 & 16 & 69 \\
\hline$-90 \%$ confidence limit & 70 & -72 & 2 & 55 \\
\hline
\end{tabular}

Note: $1 \mathrm{MPa}=145$ psi.

incorporated, shows a nearly steady or slightly increasing plastic viscosity with time, and a significantly smaller increase in yield stress (for the second reference mixture) 


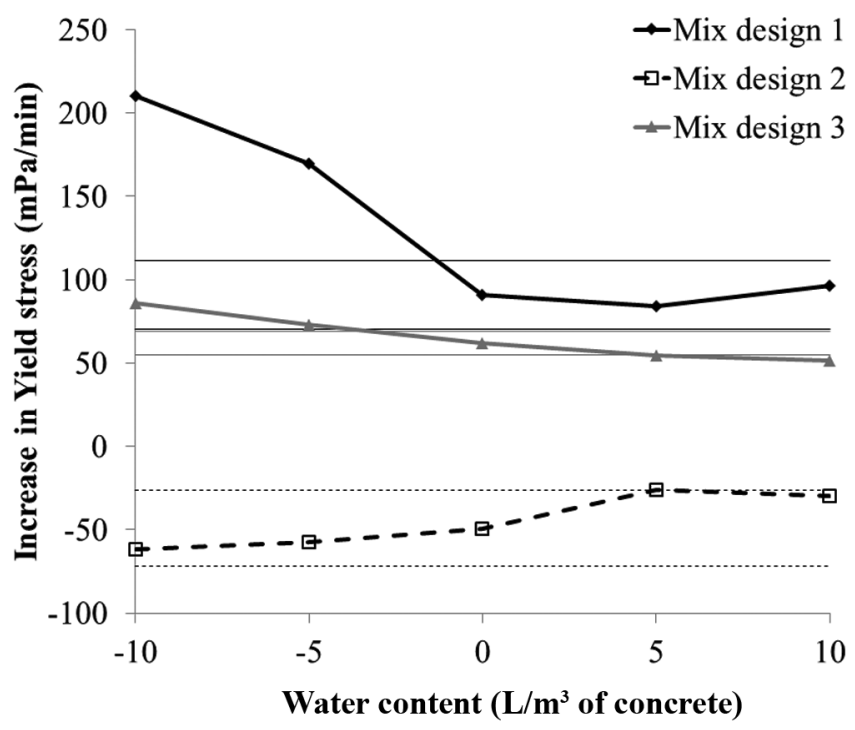

Fig. 3-Variation of increase of yield stress with time, as function of change in water content. (Note: $1 \mathrm{MPa}=145$ psi; $1 \mathrm{~L} / \mathrm{m}^{3}=0.202 \mathrm{gal} . / \mathrm{yd}^{3}$.)

and even a decrease in yield stress with time (first reference mixture), rendering the cement paste more fluid over time.

From the confidence intervals in Table 3, it can also be seen that the repeatability of the measurements is good. The standard deviation of the slopes of yield stress and plastic viscosity with time (refer to Table 3 ) is similar for Mixture Designs 2 and 3, resulting in confidence intervals of similar size. Mixture Design 1 shows a larger confidence interval, but the absolute values of increase in yield stress and plastic viscosity are also substantially higher.

\section{Variations in water content}

The quantity of water is the most used parameter in robustness studies, as most practical issues can be related to an incorrect or inadequate assessment of the moisture content of the fine aggregates. In this project, the amount of water varied in the mixture designs was $\pm 21 \mathrm{~mL}(0.71 \mathrm{fl} \mathrm{oz}$.) and $\pm 42 \mathrm{~mL}$ ( $1.42 \mathrm{fl} \mathrm{oz}$.), corresponding to $\mathrm{a} \pm 5$ and $\pm 10 \mathrm{~L}$ difference for $1 \mathrm{~m}^{3}$ of the corresponding concrete mixtures (or \pm 1.01 and $\pm 2.02 \mathrm{gal}$. for $1 \mathrm{yd}^{3}$ of corresponding concrete). Figures 3 and 4 show respectively the increase in yield stress and increase in plastic viscosity with elapsed time. The thick black and gray lines with markers represent the results of a water content variation. The corresponding thin black and gray lines represent the $90 \%$ confidence intervals established in Table 3, and are an indication on the significance of a change in water content. Focusing on Mixture Designs 1 and 3, both based on the powder-type principle, but with different ratios of $w / p$ and cement-powder ratios, similar conclusions can be drawn. More water reduces the slope of yield stress and plastic viscosity with time, which is significant for both parameters for Mixture Design 3. For Mixture Design 1, the larger increase in yield stress with time is manifested at decreasing water contents, while the slower increase in plastic viscosity is visible at increasing water contents. Also, the differences are more substantial for Mixture Design 1 than for Mixture Design 3. The change

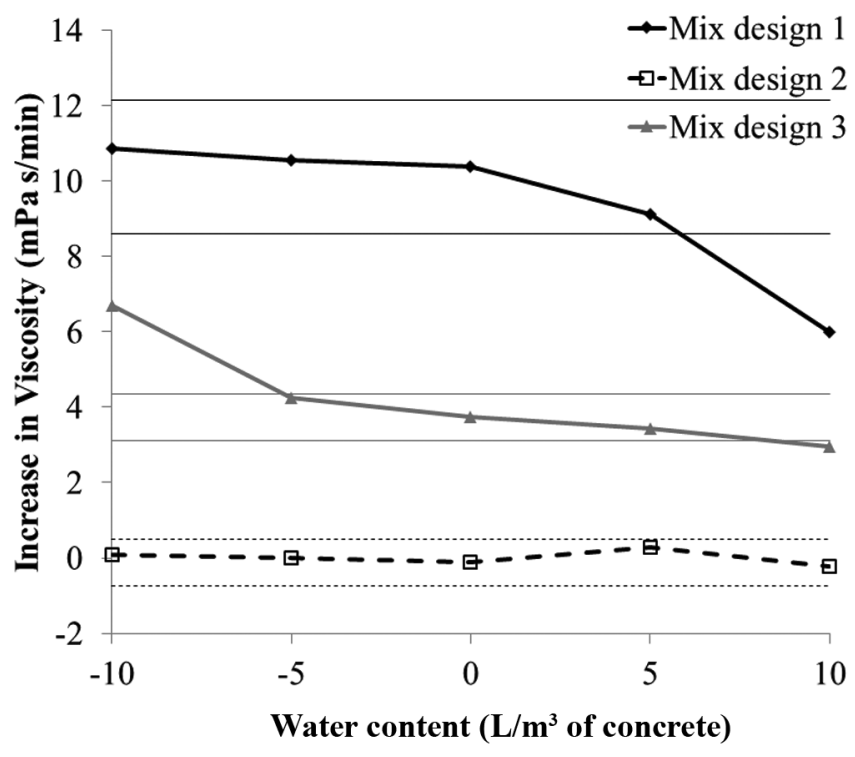

Fig. 4-Variation of increase of plastic viscosity with time, as function of change in water content. (Note: $1 \mathrm{MPa}=145 \mathrm{psi}$; $1 \mathrm{~L} / \mathrm{m}^{3}=0.202 \mathrm{gal} . / \mathrm{yd}^{3}$.)

of yield stress and plastic viscosity with time is typically attributed to slowly continuing hydration, creating calciumsilica-hydrate (C-S-H) bridges between cement particles, as well as non-chemical connections between cement particles. ${ }^{13,38}$ In mixtures with lower water contents, the inter-particle spacing is smaller, leading to a higher chance of C-S-H bridging and potentially a stronger connection between the particles. As a result, for the applied shear rate (approximately $100 \mathrm{~s}^{-1}$ ) and with a decreasing water content, an increasing number of particles can no longer be separated, leading to an increase in yield stress and plastic viscosity.

For Mixture Design 2, however, no significant changes in the change of rheological properties with time are observed, as all points fall in between the $90 \%$ confidence limits. For the reference mixture, the plastic viscosity did barely vary with time, and changing the water content does not seem to affect this evolution. The yield stress decreases with time, which can be attributed to different polymers in SP 2, which become active at different times. This time release of dispersing molecules can inhibit or slow down the formation of C-S-H bridges, leading to the constant or decreasing rheological properties. Furthermore, the $w / p$ in Mixture Design 2 is higher compared to Mixture Designs 1 and 3, which could also reduce the influence of the water content.

\section{Variations in SP dosage}

The sensitivity of the time-evolution of the rheological properties to a change in SP content is measured by changing the SP content with $\pm 5 \%$ and $\pm 10 \%$, relative to the reference value. From previous work, ${ }^{50}$ it was concluded that a change in SP content mainly affected the yield stress at 15 minutes. Figure 5 shows that the yield stress increases faster with time with increasing SP content (not considering the $-10 \%$ SP for Mixture Design 1). It can be argued herein that with increasing SP content, a larger portion of the cement surface is covered, which also means that more SP can be overgrown with hydration products over time, leading to a 


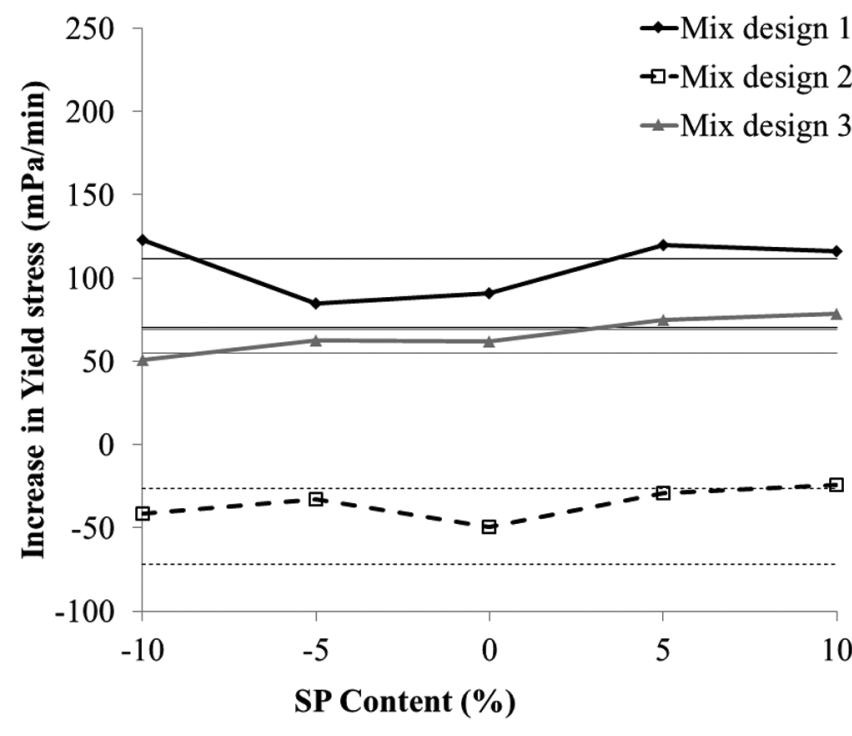

Fig. 5-Variation of increase of yield stress with time as function of change in SP content. (Note: $1 \mathrm{MPa}=145$ psi.)

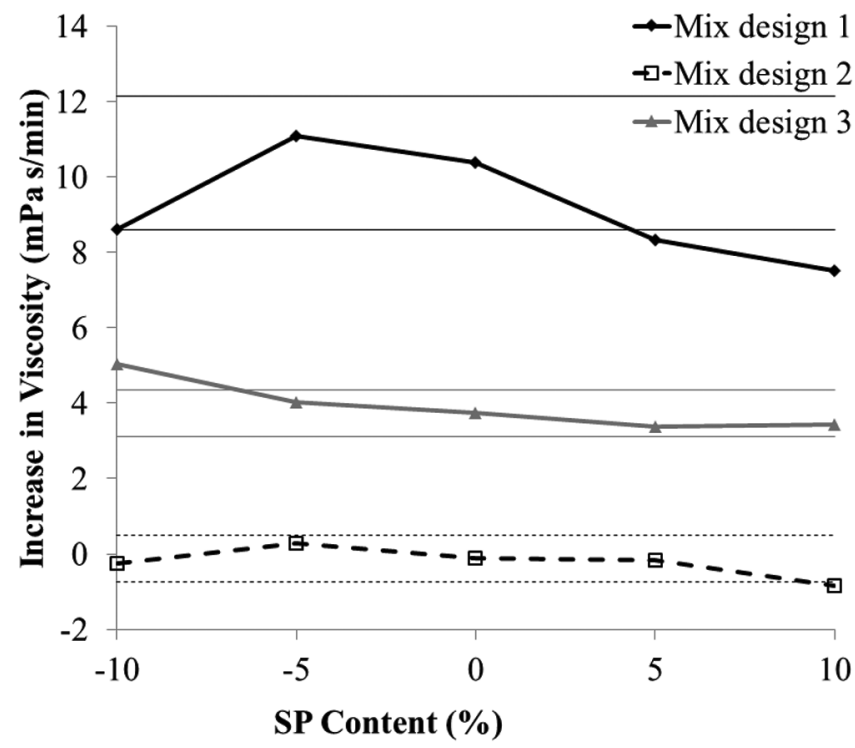

Fig. 6-Variation of increase of plastic viscosity with time, as function of change in SP content. (Note: $1 \mathrm{MPa}=145 \mathrm{psi}$.)

larger loss of efficiency for the yield stress. For the plastic viscosity change as a function of time (Fig. 6), however, the opposite trend is observed: increasing the SP content leads to a slower increase of plastic viscosity with time (again, not considering the $-10 \%$ SP for Mixture Design 1). The observed effect on plastic viscosity could potentially be due to a decrease in water available to flow, as more and larger particle clusters will be present with lower SP contents, entrapping more water. Furthermore, the changes induced by the modification of the SP content appear smaller than those induced by the water amount.

\section{Variation in adding time of SP}

The adding time of the SP can have a significant influence on the rheological properties of the mixture. It has been shown that in most cases, the SP is more effective in reducing yield stress when it is added in a delayed fashion. It

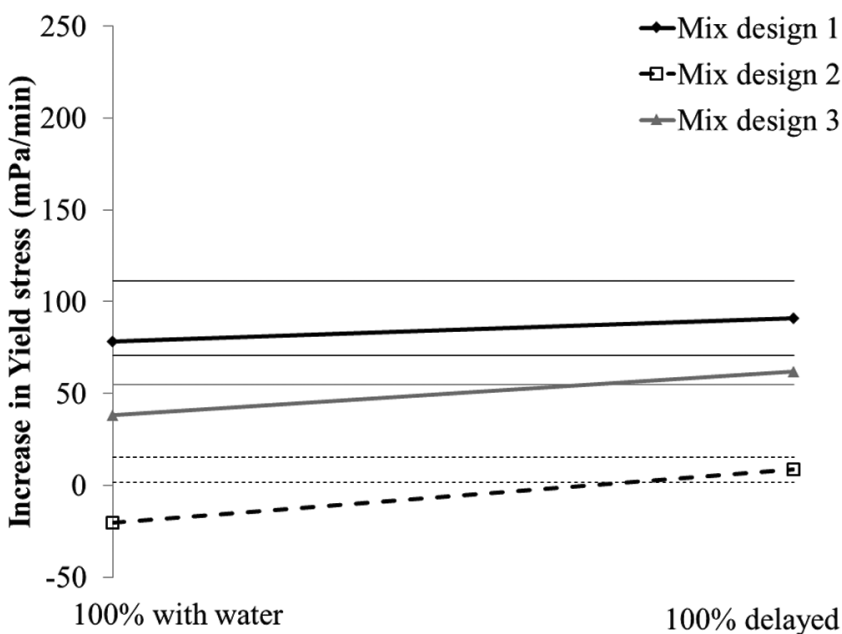

Adding time SP

Fig. 7-Variation of yield stress with time, as function of addition time of superplasticizer $(100 \%$ with water, or delayed by 2.5 minutes). (Note: $1 \mathrm{MPa}=145 \mathrm{psi}$.)

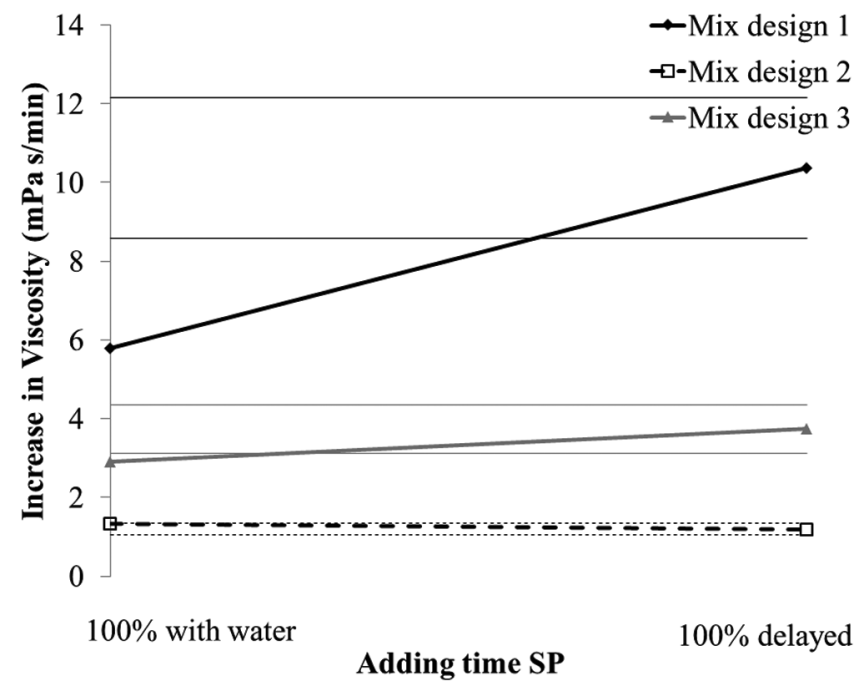

Fig. 8-Variation of plastic viscosity with time, as function of addition time of superplasticizer (100\% with water, or delayed by 2.5 minutes). (Note: $1 \mathrm{MPa}=145 \mathrm{psi}$.)

has been postulated that in case of immediate addition (with the mixing water), parts of the SP get intercalated between the initial hydration products formed. A small delay allows for hydration products to form prior to the SP attaching to a surface. In previous work by the authors, ${ }^{50}$ it has been shown that the plastic viscosity is largely affected by delaying the addition of the SP. Figures 7 and 8 compare the increase in yield stress and plastic viscosity with time respectively between a 2.5-minute delayed addition of the SP, and an equal amount of SP physically mixed in the mixing water prior to contact with the solid particles of the cement paste. A smaller increase in yield stress and in plastic viscosity with time for Mixture Designs 1 and 3 can be observed, in case of an immediate addition of the SP. It seems that when less of the SP is intercalated within the hydration products formed in the first 2.5 minutes, more of its efficiency is lost over a more extended time. 
Table 4-Effect of adding time on increase in yield stress and plastic viscosity with time, for both Mixture Designs 1 and 2, with both SP types

\begin{tabular}{c|c|c|c|c}
\hline & \multicolumn{2}{|c|}{ SP 1 } & \multicolumn{2}{c}{ SP 2 } \\
\cline { 2 - 5 } & With water & Delayed & With water & Delayed \\
\hline $\begin{array}{c}\text { Increase in yield stress } \\
\text { Mixture Design 1, } \\
\mathrm{MPa} / \text { min }\end{array}$ & 78 & 101 & -33 & 144 \\
\hline $\begin{array}{c}\text { Increase in yield stress } \\
\text { Mixture Design 2, } \\
\mathrm{MPa} / \text { min }\end{array}$ & -18 & 196 & -20 & 9 \\
\hline $\begin{array}{c}\text { Increase in plastic } \\
\text { viscosity Mixture } \\
\text { Design 1, MPas/min }\end{array}$ & 5.8 & 11.0 & 0.7 & 1.2 \\
\hline $\begin{array}{c}\text { Increase in plastic } \\
\text { viscosity Mixture } \\
\text { Design 2, MPas/min }\end{array}$ & 2.5 & 2.2 & 1.3 & 1.2 \\
\hline
\end{tabular}

Note: $1 \mathrm{MPa}=145 \mathrm{psi}$

In addition to the already-mentioned results, Mixture Designs 1 and 2 were repeated, but the SP type was reversed. In other words, the influence of the adding time of the SP was also investigated on Mixture Design 1 with SP 2 and Mixture Design 2 with SP 1. No VMA was employed, and the SP dosages were adjusted to ensure a mini-slump flow of $330 \mathrm{~mm}$ (11.8 in.) for the delayed SP addition. Similar as in Fig. 7, Table 4 shows a slower increase in yield stress (or a decrease) when the SP is added with the water compared to the delayed addition, regardless of the SP type or mixture design. However, for the plastic viscosity, a slower increase in plastic viscosity with time is noted for Mixture Design 1 in case of intermixing the SP with the water (Fig. 8), while for Mixture Design 2, a slightly larger increase in plastic viscosity is noted when adding the SP with all mixing water. Table 4 shows that the behavior of the plastic viscosity increase with time is more related to the mixture design, as regardless of which SP used, the qualitative behavior is similar for each mixture design.

\section{Variations in mixing energy: mixing time and mixing speed}

Modifications in the mixing procedure were also investigated by either changing the mixing time, or mixing speed (only for Mixtures 1 and 3). The mixing procedures are described in Table 2. For Mixture Designs 1 and 3, the modifications in mixing energy appear not to have a major effect on the change in rheological properties with time (Fig. 9 and 10). For Mixture Design 2, a slightly slower increase in yield stress and a slightly faster increase in plastic viscosity with time are observed for the shorter mixing time. For the longer mixing time, a reduction in the rate of change of the plastic viscosity is noticed. A potential hypothesis for this behavior is as follows: decreasing mixing time results in less dispersing of the particles and more water entrapped in the particle clusters. This may lead to a faster increase in plastic viscosity with time, and vice-versa for the longer mixing time. For the yield stress, however, more particles remain flocculated when the mixing time is shorter, potentially reducing the amount of adsorbed SP, keeping more SP

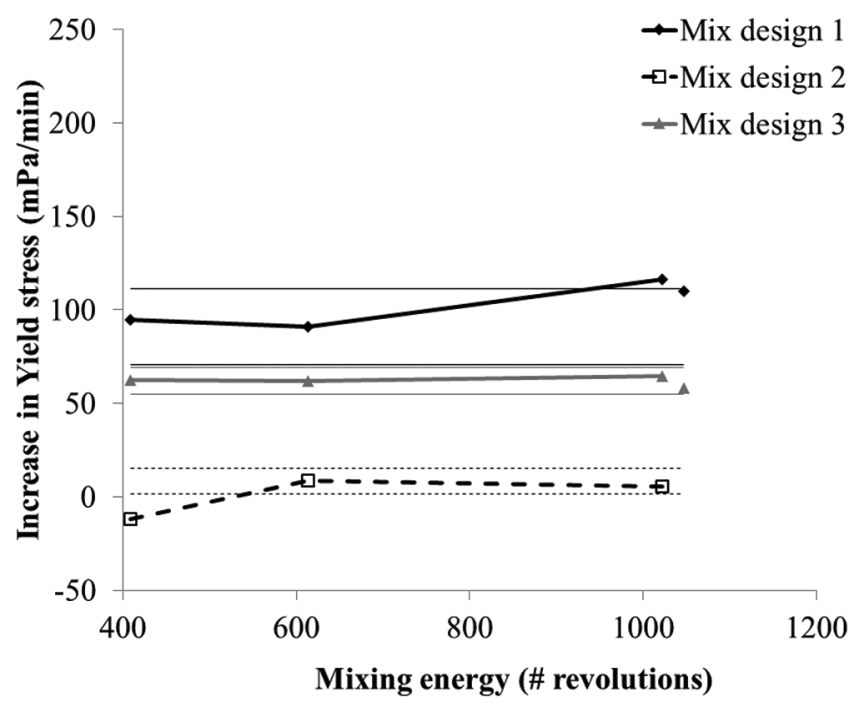

Fig. 9-Variation of yield stress with time, as function of number of revolutions in Hobart mixer. (Note: $1 \mathrm{MPa}=$ 145 psi.)

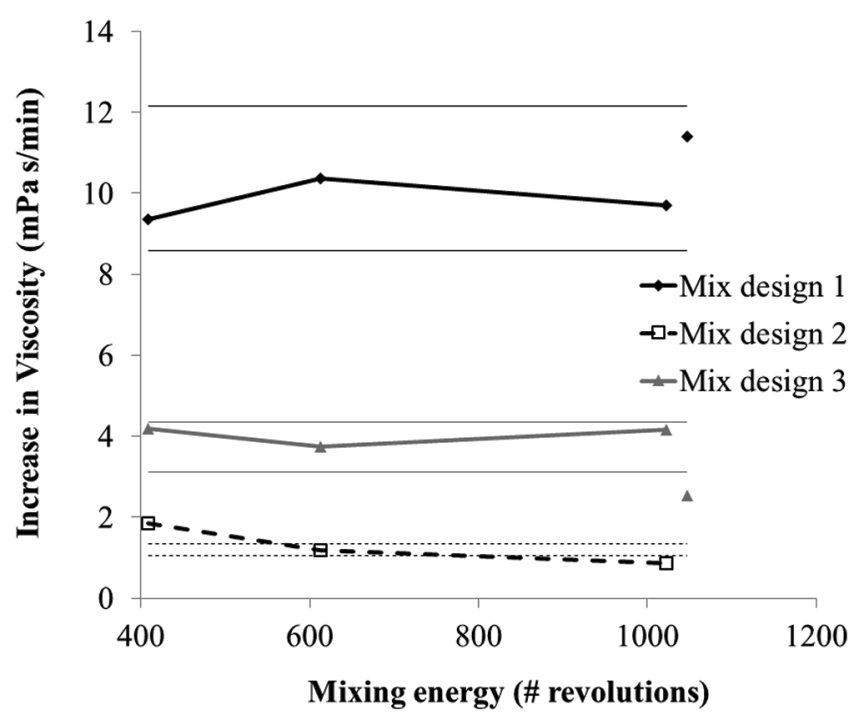

Fig. 10-Variation of plastic viscosity with time, as function of number of revolutions in Hobart mixer. (Note: $1 \mathrm{MPa}=$ 145 psi.)

available in the suspension which can reduce the increase in yield stress with time (or lead to a decrease in yield stress with time as observed).

\section{COMPARISON WITH CHANGES IN INITIAL RHEOLOGICAL PROPERTIES}

As shown in the previous sections, the distinction between SP 1 and SP 2 is very clear, and some of the conclusions need to be drawn separately for each of the SP. In this section, the time-evolution results are compared to the sensitivity of the initial rheological properties to the studied parameters, as described in Asghari et al. ${ }^{50}$

\section{Variations in water content}

For Mixture Designs 1 and 3 (SP 1), the amount of water appears to have a significant influence on the evolution of yield stress and plastic viscosity with time. Increasing the 
water content results in a lower yield stress and plastic viscosity at 15 minutes, and slows down the increase of these rheological properties with time. As a result, the rheological properties at later age are even more influenced by a modification of the water content, as both the initial rheological properties and their time evolution are influenced in the same way. For Mixture Design 2 though, the change in water content only appears to affect the initial rheological properties, while the evolution with time remains unaffected.

\section{Adding time of SP}

For the initial rheological properties, especially for Mixture Designs 2 and 3, the adding time of the SP was at least as important, or even more important than the changes in water content. ${ }^{50}$ The time-evolution of the plastic viscosity compensates for the difference in initial plastic viscosity for the mixture designs with SP 1. As shown in Asghari et al., ${ }^{50}$ a substantially higher plastic viscosity is obtained when SP 1 is added with the mixing water, but from the results reported herein, the plastic viscosity increases at a slower rate with time. For Mixture Design 1, at 45 minutes, the plastic viscosity with the delayed addition is higher than for the mixture with initial addition. For Mixture Design 3, the plastic viscosity values at 60 minutes of age show a difference of $0.038 \mathrm{~Pa} \mathrm{~s}$, compared to $0.072 \mathrm{~Pa} \mathrm{~s}$ at 15 minutes. The effects on the yield stress are of minor importance, with a slightly more important increase in yield stress with time when the addition is delayed. For Mixture Design 2 though, mainly the yield stress is affected by modifying the adding time of the SP, but the difference in yield stress increase with time is minor compared to the differences in initial rheological properties.

\section{Amount of SP}

The amount of SP has a large influence on the yield stress. Overshooting the SP content leads to a lower initial yield stress, but time appears to compensate for this by a slightly larger increase of yield stress with time. However, the difference in slope of yield stress with time is insufficient to overcome the large differences in initial yield stress. For the plastic viscosity, the induced changes are rather minor compared to the influence of water and SP adding time.

\section{Mixing time}

The mixing time has no significant influence on the change in yield stress and plastic viscosity with time for mixtures with SP 1, maintaining the difference in initial rheological properties over time. For Mixture Design 2, the differences are deemed significant, but the difference in the time evolution of the rheological properties is not substantial compared to the difference in the initial rheological properties. As a result, any difference in initial rheological properties induced by the mixing time appears to be maintained over time.

\section{CONCLUSIONS}

By means of three mixture designs based on the powdertype and VMA-type approaches, the sensitivity of the change of yield stress and plastic viscosity with time of cement pastes with SCC consistency was investigated. From this research, the following conclusions can be drawn:

- A significant difference has been noted for the two different superplasticizers employed. Not only is the time-dependent behavior different, the response of the mixtures made with the different SP to changes in other parameters is also different. As example, for the VMA-type mixtures made with the long workabilityretention SP, the change in yield stress and plastic viscosity with time appears not significantly affected by either a change in water or SP content.

- For the mixtures with the short workability retention SP, a change in water content significantly affects the increase of both yield stress and plastic viscosity with time: a reduction in water content results in a faster increase in rheology, while an increase in water results in a slower increase in rheology. As a result, any influence of water on the initial rheological properties either remains constant (SP 2), or gets amplified (SP 1). This can be attributed to the increased inter-particle spacing when more water is added, resulting in less connections growing between cement particles.

- The adding time of the SP is the second most important factor influencing the change of yield stress and plastic viscosity with time: in case of a delayed addition, these properties increase faster with time. As a result, the beneficial effect of delaying the SP addition on the initial rheological properties is reduced or even removed over time. Immediate addition of SP results in more intercalation of the SP in between hydration products immediately after mixing. This renders a delayed addition more efficient. However, with time, more hydration products are formed and as more of the SP is "active" in case of a delayed addition, it is speculated that more SP gets overgrown with time.

- For Mixture Designs 1 and 3 (SP 1), increasing the amount of SP results in a faster increase in yield stress with time; however, the change of yield stress increase with time is too small to compensate for the significant change in initial yield stress due to an increase in SP addition. The hypothesis for this behavior is similar to the differences between immediate and delayed addition: if more SP is added, more SP can be overgrown, resulting in a faster decline in efficiency. The changes in the increase of plastic viscosity with time are of minor importance.

- Changing the mixing energy appeared to have a minor, less significant importance on the change in rheological properties with time. A reduction in mixing energy could lead to more entrapped water as fewer flocs of cement particles are broken, and a faster increase in plastic viscosity with time was noted for Mixture Design 2 (the changes for Mixture Designs 1 and 3 were insignificant). However, fewer deflocculated particles results in less exposed surface, and thus a reduction in the adsorbed $\mathrm{SP}$ in the system. Although it was not explicitly noticed for SP 2, a reduction in (total) SP 1 content leads to a slower increase in yield stress with time. Applying this principle on the influence of a shorter mixing duration 
can explain why the yield stress increases slower with time. However, the changes induced in the time evolution in rheological properties are insufficient to either reduce or amplify the difference in initial rheological properties.

\section{AUTHOR BIOS}

Azadeh Asghari is Graduate Research Assistant and a PhD Candidate in the Department of Civil, Architectural, and Environmental Engineering at Missouri University of Science and Technology (Missouri S\&T), Rolla, MO. She has been a member of the Missouri S\&T Student Chapter - ACI since 2013. Her research interests include the behavior of highly workable concrete in fresh state, rheology of cementitious materials, and thixotropy of complex materials and suspensions.

Dimitri Feys is an Assistant Professor in the Department of Civil, Architectural, and Environmental Engineering at Missouri S\&T since January 2013. He received his BSc and MSc in 2004 and his PhD in 2009 from Ghent University, Ghent, Belgium. He is a member of ACI Committees 237, Self-Consolidating Concrete; 238, Workability of Fresh Concrete; 309. Consolidation of Concrete; and ACI Subcommittee 211-P, Guide for Selecting Proportions for Pumpable Concrete. His research interests include mixture design, workability, rheology, and placement of concrete.

Geert De Schutter is a Senior Full Professor of Concrete Technology and ERC Advanced Grant Holder at Ghent University, where he received his MS in 1990 and his PhD in 1996 in civil engineering. He is member of ACI Committees 231, Properties of Concrete at Early Ages, and 237, SelfConsolidating Concrete. He received the ACI Arthur R. Anderson Medal in 2014. His research interests include rheology and casting, hydration and microstructure development, and durability of cementitious materials.

\section{ACKNOWLEDGMENTS}

The authors would like to acknowledge the National University Transportation Center at Missouri S\&T and the Science Foundation in Flanders (FWO) for the financial support of this project.

\section{REFERENCES}

1. Emborg, M., and Simonsson, P., Carlswärd, J.; and Nilsson, M., "Industrial Casting of Bridges Combining New Production Methods and Materials, Like a Robust SCC, Utilizing Lean Construction Principles," Proceedings of the 5th International RILEM Symposium on Self-Compacting Concrete, Ghent, Belgium, 2007, pp. 485-491.

2. Bonen, D.; Deshpande, Y.; Olek, J.; Shen, L.; Struble, L.; Lange, D.; and Khayat, K., "Robustness of Self-Consolidating Concrete," Proceedings of the 5th International RILEM Symposium on Self-Compacting Concrete, Ghent, Belgium, 2007, pp. 33-42.

3. Gettu, R.; Nawaz Shareef, S.; and Ernest, K. J. D., "Evaluation of the Robustness of SCC," Indian Concrete Journal, V. 83, No. 6, 2009, pp. 13-19.

4. Rigueira, J. W.; García-Taengua, E.; and Serna-Ros, P., "Self-Consolidating Concrete in Continuous Production Regarding Fresh and Hardened State Properties," ACI Materials Journal, V. 106, No. 3, May-June 2009, pp. 301-307.

5. Nunes, S.; Figueiras, H.; Oliveira, P. M.; Coutinho, J. S.; and Figueiras, J., "A Methodology to Assess Robustness of SCC Mixtures," Cement and Concrete Research, V. 36, No. 12, 2006, pp. 2115-2122. doi: 10.1016/j. cemconres.2006.10.003

6. Billberg, P., "Increase of SCC Robustness to Varying Aggregate Moisture Content Using VMA," Proceedings of the 2nd International Symposium on SCC, Beijing, China, 2009, pp. 473-493.

7. Naji, S.; Hwang, S.-D.; and Khayat, K. H., "Robustness of SelfConsolidating Concrete Incorporating Different Plastic ViscosityEnhancing Admixtures," ACI Materials Journal, V. 108, No. 4, July-Aug. 2011, pp. 432-438.

8. Sahmaran, M.; Yurtseven, A.; and Yaman, I. O., "Workability of Hybrid Fiber Reinforced Self-Compacting Concrete," Building and Environment, V. 40, No. 12, 2005, pp. 1672-1677. doi: 10.1016/j.buildenv.2004.12.014

9. Ferraris, C. F.; Obla, K. H.; and Hill, R., "The Influence of Mineral Admixtures on the Rheology of Cement Paste and Concrete," Cement and Concrete Research, V. 31, No. 2, 2001, pp. 245-255. doi: 10.1016/ S0008-8846(00)00454-3

10. Han, S.; Yan, P. Y.; and Kong, X. M., "Study on the Compatibility of Cement-Superplasticizer System Based on the Amount of Free Solution,"
Science China. Technological Sciences, V. 54, No. 1, 2011, pp. 183-189. doi: 10.1007/s11431-010-4174-2

11. Rubio-Hernández, F. J.; Velázquez-Navarro, J. F.; and OrdonezBelloc, L. M., "Rheology of Concrete: A Study Case Based upon the Use of the Concrete Equivalent Mortar," Materials and Structures, V. 46, No. 4, 2013, pp. 587-605. doi: 10.1617/s11527-012-9915-1

12. Sheinn, A. M.; Ho, D. W.; and Tam, C. T., "Rheological Model for Self-Compacting Concrete-Paste Rheology," Proceedings of the 27th Conference on Our World in Concrete and Structures, Singapore, 2002.

13. Wallevik, J. E., "Rheological Properties of Cement Paste: Thixotropic Behavior and Structural Breakdown," Cement and Concrete Research, V. 39, No. 1, 2009, pp. 14-29. doi: 10.1016/j.cemconres.2008.10.001

14. Tattersall, G. H., and Banfill, P. F. G., The Rheology of Fresh Concrete, Pitman, London, UK, 1983.

15. Banfill, P. F. G., "A Viscometric Study of Cement Pastes Containing Superplasticizers with a Note on Experimental Techniques," Magazine of Concrete Research, V. 33, No. 114, 1981, pp. 37-47. doi: 10.1680/ macr.1981.33.114.37

16. Douglas, R.; Gregori, A.; Sun, Z.; Bonen, D.; and Shah, S. P., "The Effect of Ingredients and Shear History on the Thixotropic Rate of Rebuilding of SCC," Proceedings of the 2nd North American Conference and 4th International RILEM Conference on Self-Consolidating Concrete, Chicago, IL, 2005, pp. 591-596.

17. Billberg, P., "Influence of Powder Type and VMA Combination on Certain Key Fresh Properties of SCC," Proceedings of 9th International Symposium on High Performance Concrete, Rotorua, New Zealand, 2011.

18. Li, L. G., and Kwan, A. K. H., "Concrete Mix Design Based on Water Film Thickness and Paste Film Thickness," Cement and Concrete Composites, V. 39, No. 5, 2013, pp. 33-42. doi: 10.1016/j.cemconcomp.2013.03.021

19. Banfill, P. F. G., "A Discussion of the Papers "Rheological Properties of Cements Mixes' by M. Damion and D. M. Roy," Cement and Concrete Research, V. 9, No. 6, 1979, pp. 795-796. doi: 10.1016/0008-8846(79)90075-9

20. Flatt, R. J., "Towards a Prediction of Superplasticized Concrete Rheology," Materials and Structures, V. 37, No. 5, 2004, pp. 289-300. doi: 10.1007/BF02481674

21. Lei, L., and Plank, J., "Synthesis, Working Mechanism and Effectiveness of a Novel Cycloaliphatic Superplasticizer for Concrete," Cement and Concrete Research, V. 42, No. 1, 2012, pp. 118-123. doi: 10.1016/j. cemconres.2011.09.003

22. Zingg, A.; Winnefeld, F.; Holzer, L.; Pakusch, J.; Becker, S.; and Gauckler, L., "Adsorption of Polyelectrolytes and Its Influence on the Rheology, Zeta Potential, and Microstructure of Various Cement and Hydrate Phases," Journal of Colloid and Interface Science, V. 323, No. 2, 2008, pp. 301-312. doi: 10.1016/j.jcis.2008.04.052

23. Bonen, D., and Shah, S. P., "Fresh and Hardened Properties of Self-Consolidating Concrete," Progress in Structural Engineering Materials Journal, V. 7, No. 1, 2005, pp. 14-26. doi: 10.1002/pse.186

24. Hanehara, S., and Yamada, K., "Interaction between Cement and Chemical Admixture from the Point of Cement Hydration, Adsorption Behavior of Admixture, and Paste Rheology," Cement and Concrete Research, V. 29, No. 8, 1999, pp. 1158-1165. doi: 10.1016/ S0008-8846(99)00004-6

25. Aitcin, P. C. A.; Jolicoeur, C.; and McGregor, J. G., "Superplasticizers: How They Work and Why They Occasionally Don't," Concrete International, V. 16, No. 5, May 1994, pp. 45-52.

26. Roy, D. M., and Asaga, K., "Rheological Properties of Cement Mixes: III-The Effects of Mixing Procedures on Viscometric Properties of Mixes Containing Superplasticizers," Cement and Concrete Research, V. 9, No. 6, 1979, pp. 731-739. doi: 10.1016/0008-8846(79)90068-1

27. Jones, T. E. R., and Taylor, S. A., "A Mathematical Model Relating the Flow Curve of a Cement Paste to Its Water/Cement Ratio," Magazine of Concrete Research, V. 29, No. 101, 1977, pp. 207-212. doi: 10.1680/ macr.1977.29.101.207

28. Yamada, K.; Ogawa, S.; and Hanehara, S., "Controlling of the Adsorption and Dispersing Force of Polycarboxylate-Type Superplasticizer by Sulfate Ion Concentration in Aqueous Phase," Cement and Concrete Research, V. 31, No. 3, 2001, pp. 375-383. doi: 10.1016/ S0008-8846(00)00503-2

29. Yamada, K.; Ogawa, S.; and Hanehara, S., "Working Mechanism of Poly-Beta-Naphthalene Sulfonate and Polycarboxylate Superplasticizer Types from Point of Cement Paste Characteristics," Proceedings of the 6th CANMET/ACI International Conference on Superplasticizers and Other Chemical Admixtures in Concrete, SP-195, American Concrete Institute, Farmington Hills, MI, 2000, pp. 351-366.

30. Uchikawa, H.; Sawaki, D.; and Hanehara, S., "Influence of Kind and Added Timing of Organic Admixture on the Composition, Structure and Property of Fresh Cement Pastes," Cement and Concrete Research, V. 25, No. 2, 1995, pp. 353-364. doi: 10.1016/0008-8846(95)00021-6 
31. Kim, B. G.; Jiang, S.; Jolicoeur, C.; and Aitcin, P. C., "The Adsorption Behavior of PNS Superplasticizer and Its Relation to Fluidity of Cement Paste," Cement and Concrete Research, V. 30, No. 6, 2000, pp. 887-893. doi: 10.1016/S0008-8846(00)00256-8

32. Jolicoeur, C.; Sharman, J.; Otis, N.; Lebel, A.; Simard, M. A.; and Page, M., "The Influence of Temperature on the Rheological Properties of Superplasticized Cement Pastes," Proceedings of the 5th International Conference on Super-plasticizer and Other Chemical Admixtures in Concrete, Rome, Italy, 1997, pp. 379-406.

33. Simard, M. A.; Nkinamubanzi, P. C.; Jolicoeur, C.; Perraton, D.; and Aïtcin, P.-C., "Calorimetry, Rheology, and Compressive Strength of Superplasticized Cement Pastes," Cement and Concrete Research, V. 23, No. 4, 1993, pp. 939-950. doi: 10.1016/0008-8846(93)90048-E

34. Hanna, E.; Lake, K.; Perraton, D.; and Aitcin, P. C., "Rheological Behavior of Portland Cement Paste in the Presence of a Superplasticizer," Proceedings of the 3rd International Conference on Superplasticizers and Other Chemicals Admixtures in Concrete, SP-119, American Concrete Institute, Farmington Hills, MI, 1989, pp. 171-188.

35. Bonen, D., and Sarkar, S. L., "The Superplasticizer Adsorption Capacity of Cement Pastes Pore Solution Composition and Parameters Affecting Flow Loss," Cement and Concrete Research, V. 25, No. 7, 1995 , pp. 1423-1434. doi: 10.1016/0008-8846(95)00137-2

36. Carlsward, J.; Emborg, M.; Utsi, S.; and Oberg, P., "Effects of Constituents on the Workability and Rheology of Self-Compacting Concrete," Proceedings of the 3rd International RILEM Symposium on Self-Compacting Concrete, O. Wallevik and I. Nielsson, eds., RILEM Publications S.A.R.L., 2003, pp. 143-153

37. Petit, J.-Y.; Khayat, K. H.; and Wirquin, E., "Coupled Effect of Time and Temperature on Variations of Yield Value of Highly Flowable Mortar," Cement and Concrete Research, V. 36, No. 5, 2006, pp. 832-841. doi: 10.1016/j.cemconres.2005.11.001

38. Roussel, N.; Ovarlez, G.; Garrault, S.; and Brumaud, C., "The Origins of Thixotropy of Fresh Cement Pastes," Cement and Concrete Research, V. 42, No. 1, 2012, pp. 148-157. doi: 10.1016/j.cemconres.2011.09.004

39. Kong, X.; Zhang, Y.; and Hou, S., "Study on the Rheological Properties of Portland Cement Pastes with Polycarboxylate Superplasticizers," Rheologica Acta, V. 52, No. 7, 2013, pp. 707-718. doi: 10.1007/ s00397-013-0713-7

40. Heikal, M.; Morsy, M. S.; and Aiad, I., "Effect of Treatment Temperature on the Early Hydration Characteristics of Superplasticized Silica Fume Blended Cement Pastes," Cement and Concrete Research, V. 35, No. 4, 2005, pp. 680-687. doi: 10.1016/j.cemconres.2004.06.012

41. Jolicoeur, C., and Simard, M. A., "Chemical Admixture-Cement Interactions: Phenomenology and Physico-Chemical Concepts," Cement and Concrete Composites, V. 20, No. 2-3, 1998, pp. 87-101. doi: 10.1016/ S0958-9465(97)00062-0

42. Kreppelt, F.; Weibel, M.; Zampini, D.; and Romer, M., "Influence of Solution Chemistry on the Hydration of Polished Clinker Surfaces-A Study of Different Types of Polycarboxylic Acid-Based Admixtures," Cement and Concrete Research, V. 32, No. 2, 2002, pp. 187-198. doi: 10.1016/S0008-8846(01)00654-8

43. Zhang, Y.; Kong, X.; Lu, Z.; Lu, Z.; and Hou, S., "Effects of the Charge Characteristics of Polycarboxylate Superplasticizers on the Adsorption and the Retardation in Cement Pastes," Cement and Concrete Research, V. 67, 2015, pp. 184-196. doi: 10.1016/j.cemconres.2014.10.004

44. Flatt, R. J., and Bowen, P., "YODEL: A Yield Stress Model for Suspensions," Journal of the American Ceramic Society, V. 89, No. 4, 2006, pp. 1244-1256. doi: 10.1111/j.1551-2916.2005.00888.x

45. Flatt, R. J., and Bowen, P., "Yield Stress of Multimodal Powder Suspensions: An Extension of the YODEL Yield Stress Model," Journal of the American Ceramic Society, V. 90, No. 4, 2007, pp. 1038-1044. doi: 10.1111/j.1551-2916.2007.01595.x

46. Gołaszewski, J., and Szwabowski, J., "Influence of Superplasticizers on Rheological Behavior of Fresh Cement Mortars," Cement and Concrete Research, V. 34, No. 2, 2004, pp. 235-248. doi: 10.1016/j. cemconres.2003.07.002

47. Struble, L., and Sun, G. K., "Viscosity of Portland Cement Paste as a Function of Concentration," Advanced Cement Based Materials, V. 2 , No. 2, 1995, pp. 62-69. doi: 10.1016/1065-7355(95)90026-8

48. Petit, J.-Y.; Wirquin, E.; and Duthoit, B., "Influence of Temperature on Yield Value of Highly Flowable Micromortars Made with Sulfonate-Based Superplasticizers," Cement and Concrete Research, V. 35, No. 2 , 2005, pp. 256-266. doi: 10.1016/j.cemconres.2004.04.025

49. Petit, J.-Y.; Khayat, K. H.; and Wirquin, E., "Coupled Effect of Time and Temperature on Variations of Plastic Viscosity of Highly Flowable Mortar," Cement and Concrete Research, V. 39, No. 3, 2009, pp. 165-170. doi: 10.1016/j.cemconres.2008.12.007

50. Asghari, A.; Ley Hernandez, A. M.; Feys, D.; and De Schutter, G., "Which Parameters, Other Than the Water Content, Influence the Robustness of Cement Paste with SCC Consistency?" Construction and Building Materials, V. 124, 2016, pp. 95-103. doi: 10.1016/j.conbuildmat.2016.07.101

51. Reiner, M., Deformation and Flow: An Elementary Introduction to Theoretical Rheology, Lewis \& Co. Limited, Great Britain, 1949.

52. Feys, D.; Wallevik, J. E.; Yahia, A.; Khayat, K. H.; and Wallevik, O. H., "Extension of the Reiner-Riwlin Equation to Determine Modified Bingham Parameters Measured in Coaxial Cylinders Rheometers," Materials and Structures, V. 46, No. 1-2, 2013, pp. 289-311. doi: 10.1617/ s11527-012-9902-6 
Reproduced with permission of copyright owner. Further reproduction prohibited without permission. 